\title{
THE APPLICATION OF QUALITY MANAGEMENT SYSTEM IN THE INSPECTION OF NATIONAL MAJOR SURVEYING AND MAPPING RESULTS
}

\author{
ChunXi Chen ${ }^{1, *}$, JiXian Zhang ${ }^{1}$, HaiTao Zhao ${ }^{1}$, YongMin Xu ${ }^{1}$, Su Yin ${ }^{1}$ \\ ${ }^{1}$ National Quality Inspection and Testing Center For Surveying and Mapping Products, 28 Lianhuachi West Road, Haidian District, \\ Beijing, China-33360883@qq.com
}

KEY WORDS : Quality management system, Quality control, ISO9001, Major surveying and mapping projects, Natural resources, Fundamental geographical conditions monitoring

\begin{abstract}
:
Today's society has entered the era of big data, and the quality of surveying and mapping results has become the focus of gov ernment departments. As the statistical results of other industries, surveying and mapping results as one of the basic data sources provide data support for government decision-making, The status of surveying and mapping projects is constantly improving. This article introduces the ISO9001 quality management system implemented by the surveying and mapping production unit, the CMA quality management system implemented by the surveying and mapping quality inspection unit, and the first-level acceptance system for the two-level inspection of surveying and mapping products. Through the cause and effect diagram, taking the quality control of the fundamental geo graphical conditions monitoring of the national major survey ing and mapping project as an example, the use method of the core tool 5M1E (Man, Machine, Material, Methods, Measurement, Environment) in the quality management system is demonstrated to prove that the quality management system plays an important role in the project. Provide reference experience for peers.
\end{abstract}

\section{INTRODUCTION}

With the rapid economic development and the improvement of the level of science and technology, The importance of surveying and mapping en gineering is constantly rising. Today's society has entered the era of big data. Surveying and mapping geographic information products are the same as the data of various industries. As one of the basic data sources, it provides the most basic support for government decision-making. The mapping data and final results directly affect the quality of the entire project, Surveying and mapping production is a highly professional work involving complicated procedures, Therefore, the surveying and mapping production unit and the government department in charge of surveying and mapping are very concerned about this problem, that is, how to take effective measures to manage the quality of surveying and mapping projects, and constantly improve the quality of surveying and mapping results.

At present, there are many researches and works on how to carry out quality management for a specific surveying and mapping project. This paper starts from the source of the quality management system. Analyze the ISO 9001 quality management system established by the surveying and mapping production unit; The CMA quality management system established by the surveying and mapping inspection unit; And The two-level inspection and quality assurance system of first-level acceptance, That is, the national standard of surveying and mapping industry required by the surveying and mapping product production unit, so as to explore the core issues of quality management. Then through the example of quality control of fundamental geographical conditions monitoring of major national mapping projects, using 5M1E tools and cause and effect diagrams, the quality control points of the project are analyzed, and how the project quality system is established and the results achieved have an inverse effect. Provide reference experience for quality inspection colleagues and quality management personnel of surveying and mapping production unit departments.

\section{QUALITY MANAGEMENT S YSTEM}

\subsection{Quality Management System IS O9001}

The ISO/TC176 committee issued the world's first international standard for quality management and quality assurance in 1987, and subsequently issued quality management technical specifications and technical reports, which are collectively known as the ISO9000 series of standards. The ISO9000 family standard contains three core standards, namely ISO9000/GB/T19000 "Quality Management System Foundation and Terminology", ISO9001/GB/T19001" Quality Management System Requirements" and ISO9004/GB/T19004 "Pursue the Organization's Continuous Success Quality Management method" (Shi, Liu, 2017). ISO9000 describes the management system as: a system that establishes policies and goals and achieves these goals. Every organization has a management system. The organization uses the management system to establish and make the organization's goals, guidelines, and policies effective. A management system should include: (1)An organizational structure with clear tasks, responsibilities and powers; (2)System processes and related resources to achieve goals; (3) A set of measures to measure and evaluate system performance through feedback results Methods; (4) The review process to ensure that the problem is corrected and the process of continuous improvement. The current version includes GB/T19000-2016/ISO9000:2015. Quality management system foundation and terminology and GB/T19001-2016/ISO9001: 2015. Quality management system requirements. In China, provincial and national surveying and mapping production units have all passed the ISO9001 quality management system certification, which proves the standardization and scientific compliance of management and ensures the quality of surveying and mapping products.

* Corresponding author 


\subsection{Quality Management System CMA}

"CMA" is short for China Metrology Certification. The Chinese government is very concerned about product quality. In order to strengthen the supervision and management of product quality, improve product quality levels, clarify product quality responsibilities, protect the legitimate rights and interests of consumers, and maintain social and economic order, China promulgated and implemented the Product Quality Law of the People's Republic of China. Article 19 of Chapter 2 of the Quality Law stipulates that: the product quality inspection agency must have the corresponding testing conditions and capabilities, and only after passing the assessment by the market supervision and management department of the people's government at or above the provincial level or its authorized department can it undertake the product quality inspection. .It can be seen from Article 19 that the Chinese government has put forward requirements for institutions engaged in quality product inspection, that is, they must pass the assessment of the government regulatory department or its authorized department before they can engage in the quality inspection of third-party products. Therefore, national and provincial surveying and mapping quality inspection agencies all hold CMA certificates recognized by the national and provincial administrative authorities. To obtain the CMA certificate, it is necessary to establish the quality management system of the quality inspection agency in accordance with the requirements of the government supervision department. The CMA quality management system is a standard designed by the Chinese government in accordance with the requirements of the internationally accepted quality management system and according to China's national conditions. Its core is Man, Machine, Material, Methods, Measurement, Environment, which is referred to as $5 \mathrm{M} 1 \mathrm{E}$ (Chapter 2.4).

\subsection{Two-level Inspection and First-level Acceptance System}

National standard (Zeng, 2009) stipulates that the surveying and mapping achievements must pass the procedure of two-level inspection and first-level acceptance. It means that the results of surveying and mapping should pass the process inspection of the production department of the surveying and mapping unit (first-level inspection), the final inspection of the quality management department of the surveying and mapping unit (second-level inspection) and the acceptance of the organization of the project management unit (first-level acceptance) or the quality of CMA inspection agency acceptance. Among them, the first-level inspection and the second-level inspection are all inspections, and the field inspections may be sample inspections. Sampling inspection is generally adopted for final acceptance (first-level acceptance).The three processes should be independent and carried out in sequence, and must not be omitted, substituted or reversed.

The final survey results are obtained after the production and quality inspection of the following process, as shown in Figure 1.As can be seen, the ISO9001 quality management system ensures that the production unit follows the system requirements in the production process, and operates scientifically to ensure product quality. The two-level inspection and first-level acceptance system specified in GB/T 24356-2009 better guarantees the quality of surveying and mapping results.

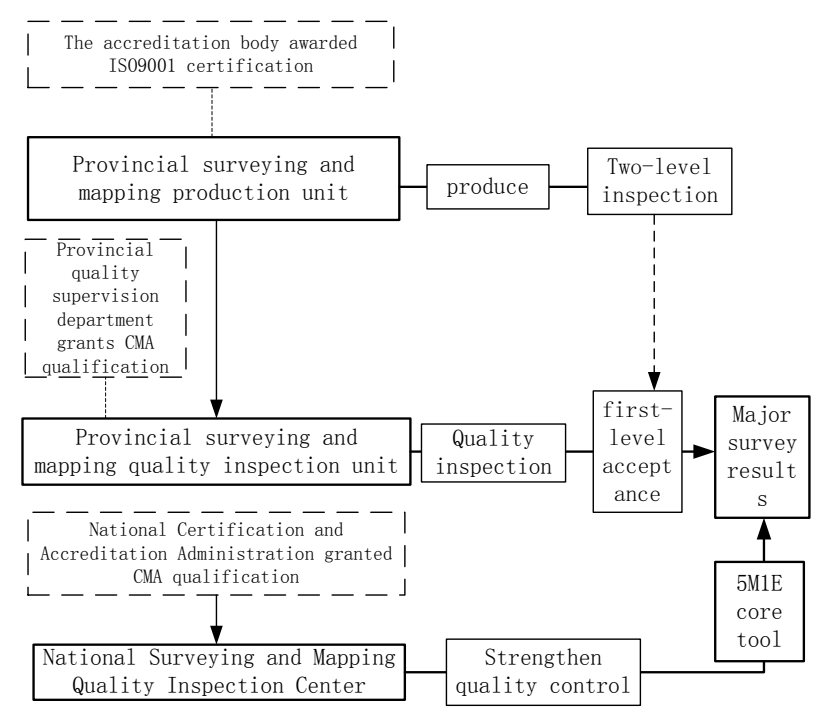

Figure 1. Flow chart of production and quality inspection of major surveying and mapping achievements

\subsection{Core Tool 5M1E}

In summary, the author found that whether the quality management system is ISO9001 or CMA, it follows a core, namely Man, Machine, Material, Methods, Measurement, Environment, referred to as $5 \mathrm{M} 1 \mathrm{E} .5 \mathrm{M} 1 \mathrm{E}$ is the six main factors that cause product fluctuations, and it is also the core of attention in domestic and foreign quality management systems

As shown in Figure 2, among these six factors, "Man" plays a leading role in product quality control. The meaning of ergonomic survey in the field of surveying and mapping is: "Man" refers to the person who produces the surveying and mapping products, the management personnel, and the quality inspection personnel. "Machine" refers to the equipment used to produce the product. Mainly includes equipment such as total stations, drones, three-dimensional laser scanners, desktop computers, etc. used in the field. "Material" refers to the original data used to manufacture products, the collected data, etc. "Method" refers to the method, standard and specification used in manufacturing the product. "Environment" refers to the workplace environment and the production environment. Generally, there is no special requirement for indoor working environment, but the influence of temperature and humidity on surveying and mapping instruments needs to be considered in field work. "Measure" refers to the activity of measuring and carrying out inspections. In quality control, these six factors are interrelated and affect each other. Only by controlling and optimizing every link can we achieve the ultimate goal of good quality control. Therefore, in the process of quality control of surveying and mapping projects, starting with $5 \mathrm{M} 1 \mathrm{E}$ and strengthening the quality control of these six elements will have a good effect. 


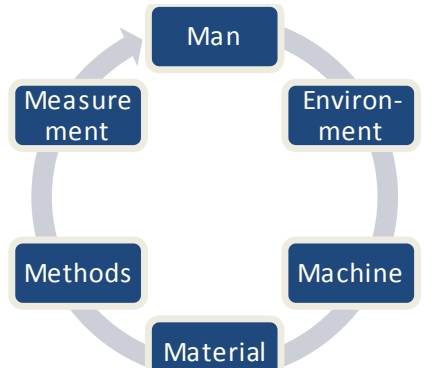

Figure 2. Core tools 5M1E

\section{QUALITY INSPECTION CASE OF FUNDAMENTAL GEOGRAPHICAL CONDITIONS MONITORING RESULTS}

The following uses the quality control of the fundamental geographical conditions monitoring results as an example, and illustrates the use of the $5 \mathrm{M} 1 \mathrm{E}$ core tool with a cause-and-effect diagram.

\subsection{The Fundamental Geographical Conditions Monitoring Results}

The Geographical National Conditions Survey is a major survey of national conditions and national strength. It is an important means to obtain comprehensive information on geographical conditions and national conditions. It is the basic work to master the basic situation of surface nature, ecology and human activities. In 2015, China launched the first national geographic and national census to grasp the surface coverage of land, forests and grass, as well as national railways and roads and other important geographical and national factors (Zhang, 2016) In accordance with the requirements of the Chinese government for the normalization of geographic national conditions monitoring, based on the data of the first geographic national census, starting from 2016, China has carried out fundamental geo graphic national conditions monitoring for three consecutive years. The achievements over the years have been applied in many aspects such as urban planning management, environmental protection and governance, natural resource management, space use control, etc. The results of fundamental geographic national conditions monitoring data include: Orthographic results, land cover classification results, geographic national conditions elements results, field survey data, remote sensing image interpretation sample results, production metadata results, etc.(Figure 3 ).The results of land cover classification in 2019 include planted land, forest and grass cover, housing construction areas, railways and roads, structures, artificial piles, deserts and bare land, waters. A total of 8 first-level categories, 46 second-level categories and 86 third-level category polygonal elements are stored in the Geodatabase format.

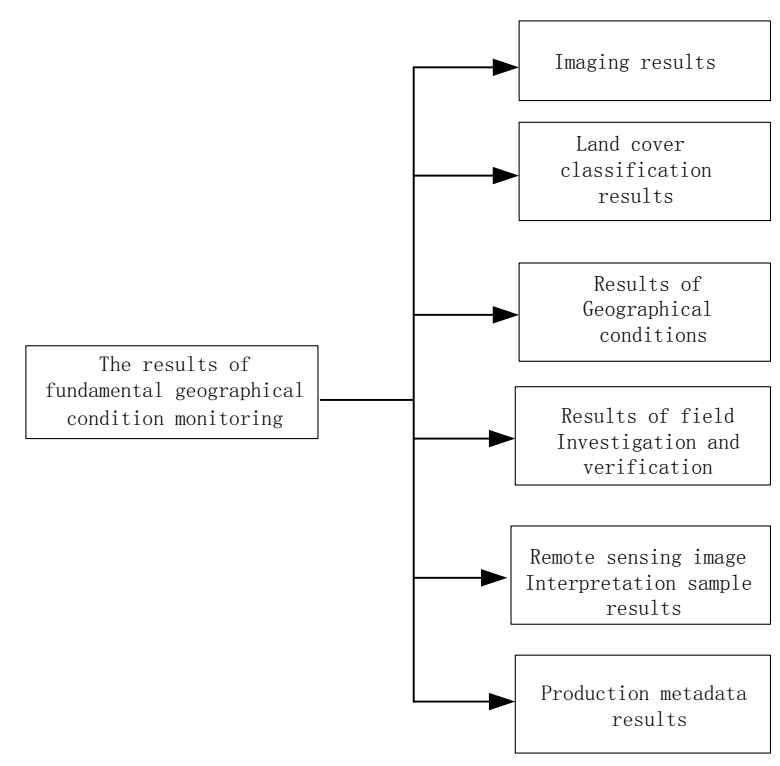

Figure 3. The fundamental geographic and national conditions monitoring data results

\subsection{Quality Control Causality Diagram Analysis}

As can be seen from Chapter 2 above, the surveying and mapping production unit has an ISO9000 quality management system to control the quality of its production, and there is also a two-level inspection and first-level acceptance system to check the quality of the surveying and mapping results. And the acceptance unit is also a survey and mapping quality inspection agency with CMA qualification. For major projects such as fundamental geographic and national conditions monitoring, it is also necessary for the national surveying and mapping quality inspection agency to strengthen the quality control of the project Because there are more than 30 surveying and mapping production units that participate in the production of fundamental geographic national conditions monitoring results data each year, each unit has a different production mode, different provinces and cities, different characteristics, diverse results, complex procedures, and different production technology routes. Therefore, how to use $5 \mathrm{M} 1 \mathrm{E}$ core tools to grasp the nodes of quality control, control the quality of national geographic and national conditions monitoring products, and have operability?

The causality diagram, also known as the fishbone diagram, is one of the main contributions of Japanese quality management expert Ishikawa Shin. The cause and effect diagram is to summarize and analyze the various reasons that affect the quality, list the reasons with concise text and lines, and classify and analyze the many reasons (Wei, 2009). The following is a combination of the core tool $5 \mathrm{M} 1 \mathrm{E}$, and the quality control point is found through the quality control causality diagram of the fundamental geographic national conditions monitoring results in Figure 4. 


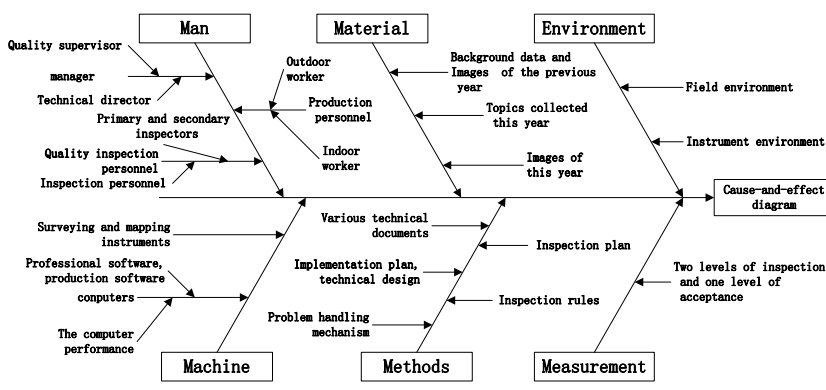

Figure 4. Fundamental geographic national conditions monitoring results quality control causality diagram

3.2.1 Man: For surveying and mapping production units, there are management personnel, production personnel, and quality inspection personnel in the project. It is important to $p$ ay attention to whether the personnel in these key positions have the monitoring technology requirements in place that will affect the quality of the results, and it is essential for them to strengthen the training of their respective positions. Also pay attention to whether there is a responsible person, the skill mastery, whether the training is sufficient, whether the personnel will operate the instrument, and whether the personnel have mastered the technical methods.

3.2.2 Machine: During the production process, the quality of the tools will affect the production schedule. It is necessary to pay attention to whether the machine equipment is operating normally, whether the field equipment model meets the requirements, whether it is within the inspection period, whether the software version is correct, and Whether the software test is qualified.

3.2.3 Materials: Pay attention to whether the information has been checked before entering the warehouse, whether the data is missing or there is a situation where it cannot be used.

3.2.4 Method: Pay attention to whether the latest version of the standards and specifications is used, whether to work in accordance with standard methods or work instructions, and whether the work instructions are written clearly and easily.

3.2.5 Measurement: Pay attention to the quality inspection carried out. In addition to the two-level inspection and the firstlevel acceptance, whether there are other measures to ensure the quality of the results.

3.2.6 Environment: Pay attention to whether the working environment meets the requirements of the unit's quality management system.

\subsection{Quality Management System for Monitoring Results of Fundamental Geographic National Conditions}

China has a vast territory, different provinces and cities have different topographic features, different vegetation distribution, and different types of land cover. And the results are diverse, the production methods of each unit are different, the equipment is different, the software is different, and the most important thing is the different experience of the production personnel. How can we ensure that the achievements of each province meet the requirements of technical design? American statistician Hugh Hart is called "the father of statistical quality control", and his quality concept is "the quality of products is not tested, but manufactured." (Qian, Wang, 2019) If serious quality problems are discovered during the final inspection stage, not only will the results become unusable, but they will also need to be re-produced, which will consume labor costs and time costs, and will also delay the country 's unified time to submit data.

In carry ing out inspection activities, the production unit follows the "two-level inspection and first-level acceptance system" proposed (Deng, 2008), and the National Surveying and Mapping Quality Inspection Center conducts process quality inspections for units undertaking all tasks nationwide And review the quality of the results. Among them, the key task of process quality inspection is to undertake the execution status and effect of the process quality inspection of the unit, to fully understand and master the monitoring production quality management and quality control situation, timely discover the universality and tendency problems that affect the quality of monitoring results, and put forward rectification opinions .The review is to further ensure the truthfulness, accuracy, reliability, and consistency of the national results by conducting targeted inspections on the results of the fundamental geographic and national monitoring data before launching the final results.

Figure 5 is the flow of production and quality inspection of the fundamental geographic monitoring and mapping project. Through the 5M1E tool, under the decomposition of Figure 4 , the idea of adding process inspection and review (Chapter 3.3) is proposed to further strengthen quality control.

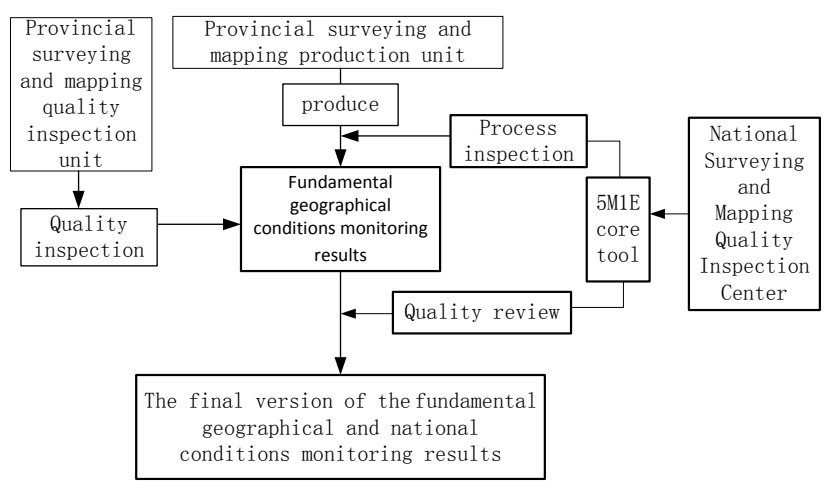

Figure 5. Fundamental geographic national conditions monitoring and mapping engineering production and quality inspection process

\subsubsection{Process Inspection}

Process quality inspection includes quality management and production process quality control. Quality management inspection includes organization and implementation, project design (or implementation plan), provincial training, design verification, collection and utilization of special data, technical problem handling, and process quality inspection. The quality control of production process inspection includes image processing, change information collection, field investigation and verification, remote sensing image interpretation samples, internal industry editing and finishing, pre-test results and other key links in process quality control (Figure 6). 


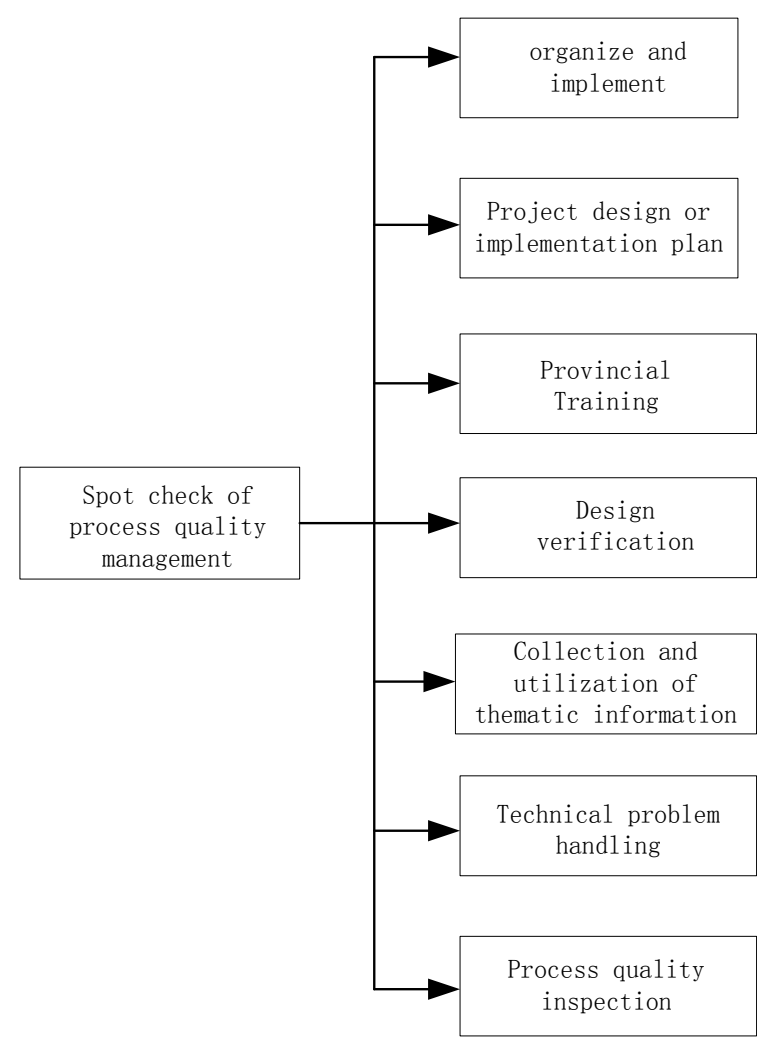

Figure 6. Inspection of quality control during production

\subsubsection{Quality review}

The quality review content mainly includes two aspects: the provincial-level acceptance inspection and the quality inspection of key monitoring results. Provincial acceptance normative inspection mainly confirms whether the provincial acceptance has fully covered various results such as digital orthophoto data, surface coverage classification data, geographic national condition element data, geographic national condition monitoring production metadata and remote sensing image interpretation sample data, etc. Whether the acceptance is independently carried out by a qualified quality inspection agency, whether the acceptance is carried out on the basis of the two-level inspection, and whether the key links such as sampling, inspection, quality assessment, and report preparation meet the requirements of the acceptance regulations. The quality inspection of key monitoring achievements involves some important inspection items of three types of monitoring achievements, such as classification data of surface coverage, geographic national condition element data, and geographic national condition monitoring production metadata.

Through the integration of $5 \mathrm{M} 1 \mathrm{E}$, we can see that on the fundamental geographic national conditions monitoring project, the country has established a major survey and mapping project quality management and control mechanism, forming a twolevel inspection of quality system, quality standards, process quality inspection, and achievement quality. The quality management system for quality review effectively guarantees the quality of the fundamental geographic and national monitoring results of major surveying and mapping results.

\subsection{Quality Control Results}

Through the process inspection proposed by the $5 \mathrm{M} 1 \mathrm{E}$ tool, problems in the fundamental geographic national conditions monitoring data were found. The production unit has more time to optimize the data and production process, effectively avoiding the similar problems from continuing to appear in production. The review is to pass the final check before handing over the final results to the country, and promptly revise the problems found before submitting them.

Carrying out process quality inspections at the provincial and national levels and found the following main problems:(1) Man: There are no full-time quality inspectors. (2) Method: The first technical verification has not been carried out. The process quality inspection did not cover the relevant technical links, such as: field investigations and internal industry editing and finishing links; the content and records of the process quality inspection were incomplete. (3) Material: Part of the publicly available thematic information has not been collected; the analysis of the thematic information has not been carried out, and the unified utilization principles have not been formulated.(4) Machine: The Electronic Total Station in use is not within the inspection period, and should be sent to the instrument verification center for re-inspection immediately.

In terms of the final quality review stage, the main problems found in the fundamental geographic and national situation monitoring data are: Orthographic results: (1) The resolution of the entire scene image after correction does not meet the requirements; (2) The phase of the image used does not meet the national technical requirements. Surface coverage achievements: (1) The collection accuracy of the road edge exceeds the limit, for example, the limit difference is 5 meters, which is now 13 meters. (2) Misclassification of patch. For example, 100,000 square meters of vegetation is classified as water. (3) New elements are missing and updated. Achievements of geographical factors: the logical relationship between bridges and roads is inaccurate, and they completely overlap with roads as required. Sample results of remote sensing image interpretation: (1) The main body of some ground photos is unclear. (2) Some ground photos indicate that the CC code is wrong. Production metadata results: (1) The main image source attribute item is incorrectly filled, and the image name is inconsistent with the image used; (2) Check the excess number of elements, including non-self-level elements, that is, the element is placed in the wrong layer.

After the errors and problems found in the process inspection are fed back to the production unit, the production unit makes timely rectifications, avoiding the situation where the major problems are not found and it is too late to make up for the stage when the final results are due. The review is the final step after acceptance, so that the "measurement" quality inspection activity includes a more complete link of final results delivery, to achieve the purpose of controlling the quality of fundamental geographic national conditions monitoring results.

\subsection{Continuous Improvement of The Quality Management System}

The quality management system is a process of continuous improvement and improvement, as is the quality control of surveying and mapping engineering. The fundamental geographical and national conditions monitoring project has been carried out for 3 consecutive years. Every year, as the 
requirements in the Ministry of Natural Resources are different, the quality management system must also be updated.

In terms of personnel, new management personnel have been replaced, and newly recruited production and technical personnel should strengthen induction training. In terms of instruments and equipment, new software or new versions of software are required, and testing needs to be carried out, and a test report that the software can be put into production is issued. In terms of data, changes in thematic information should reanalyze the principle of data utilization. In terms of methods, the technical route and technical indicators have changed, and the implementation plan and technical regulations will have certain changes. Combined with the problems that occurred during the specific implementation of control in the previous year, preventive measures should be taken in the next year to avoid similar situations. It is necessary to strengthen this input to technical personnel during technical training. In terms of measurement, the methods and methods of quality inspection will make linkage adjustments. For example, when the country carried out process quality inspections, only one batch was carried out in more than 30 provinces in the country in 2018. In 2019 , it was adjusted to carry out two batches of inspections, which effectively controlled the quality of the country.

When the project achieves quality improvement effects, it is not the end of quality improvement, but at a new level of quality, looking for new opportunities for quality improvement, reestablishing quality improvement goals, and continuing to carry out quality improvement activities.

\section{CONCLUTIONS}

With the advent of the era of big data, the surveying and mapping industry is more closely intersecting with many fields and disciplines such as ocean, minerals, forestry and other fields Government departments are increasingly concerned about the quality of surveying and mapping products produced and the results of surveying and mapping. There have been many articles on how to control the quality of specific projects, how to find out the essential problems affecting quality from the root.

The article combines years of experience in quality inspection in the surveying and mapping industry, as well as research on the concept of quality management systems at home and abroad. Carry out inspection and inspection in a targeted manner. Taking the quality control of the monitoring results of basic geographical and national conditions as an example, a causal diagram is used to analyze and explain how to use the tool of 5M1E (Man, Machine, Material, Methods, Measurement, Environment). By increasing the control of the quality of the results during the production process and after acceptance, it is proposed to increase the staged control points for process inspection and review. During the process inspection, the quality problems generated during the production process were effectively discovered, and it was pre-announced to the provincial surveying and mapping production unit in advance to avoid rework at the time of acceptance; during the review, the key issues that could not be wrong were re-checked to strengthen the quality control of the results. On the one hand these two control points make the production unit and acceptance unit pay attention to quality, on the other hand, the national surveying and mapping authority can also grasp the quality situation in the country at the production stage, which provides a reference for the final acceptance task. The reference basis was provided during the acceptance task. These ideas and practical experience have a good reference for peers en gaged in quality inspection of surveying and mapping products, quality control practitioners and production personnel.

\section{ACKNOWLEDGEMENTS}

I would like to express my gratitude to all those who helped me during the writing of this thesis. I gratefully acknowledge the help of my director, Mr. Zhang J., X., who has offered me valuable suggestions in my work. Without his patient instruction, insightful criticism and expert guidance, the completion of this thesis would not have been possible.

\section{REFERENCES}

Deng, G.Q., Ma, X.P., Ma, C.L., 2008: GB/T 18316-2008 Specifications for inspection and acceptance of quality of digital surveying and mapping achievements. China Standard Press, Beijing.

Qian, S., Wang, Y., Wang, Y.X., Dai, Y., 2019. How to control and manage the quality of surveying and mapping products under the background of information surveying and mapping, Geomatics \& Spatial Information Technology, 42(6), 240-244.

Shi, R., Liu, Y., 2017. Research on the establishment of new standard quality management system for surveying and mapping units. Annual conference of Jiangsu society of surveying and mapping geographic information. 113-114.

Wei, G., Shang, J., 2009: Quality director's practice manual. China Development Press, Beijing.

Zeng, Y.W., Tan, M.J., Tang, Y.D., 2009: GB/T 24356-2009 Specification for quality inspection and acceptance of surveying and mapping products, China Standard Press, Beijing.

ZHANG, J.X., ZHAI, L., 2016. Thinking about Normalized Geographical Conditions Monitoring. Geospatial Information, 14(4), 1-3. 